\title{
Efeito do bicarbonato de sódio no tratamento de vinhaça em AnSBBR operado a 55 e $35^{\circ} \mathrm{C}$
}

\section{Effect of the sodium bicarbonate in the treatment of vinasse in AnSBBR operated at 55 and $35^{\circ} \mathrm{C}$}

\author{
Maria Magdalena Ribas Döll \\ Professora Adjunta do Departamento de Engenharia Civil da Universidade Estadual de Ponta Grossa (UEPG), Campus de Uvaranas
}

Eugenio Foresti

Professor Titular de Hidráulica e Saneamento da Escola de Engenharia de São Carlos da Universidade de São Paulo (USP)

\begin{abstract}
Resumo
Avaliou-se a influência do bicarbonato de sódio $\left(\mathrm{NaHCO}_{3}\right)$ no desempenho do reator anaeróbio batelada sequencial com biomassa imobilizada tratando vinhaça a 55 e a $35^{\circ} \mathrm{C}$. O reator foi preenchido com espuma de poliuretano e agitado a $300 \mathrm{rpm}$. A adaptação a $55^{\circ} \mathrm{C}$ estendeu-se por 50 dias, tendo o reator sido alimentado com vinhaça (DQO de 0,3 a 1,0 g/L). Para a operação a $35^{\circ} \mathrm{C}$, procedeu-se inicialmente ao enriquecimento da população metanogênica, durante 21 dias, com substrato à base de etanol (2,5 gDQO/L). Posteriormente, cargas orgânicas volumétricas (COV) de 0,85 a 5,70 gDQO/L.d foram aplicadas no reator a $55^{\circ} \mathrm{C}$, com suplementação de 1,2 a $0,4 \mathrm{gHCO}_{3}^{-} / \mathrm{gDQO}$. A $35^{\circ} \mathrm{C}$, o reator foi submetido a $\mathrm{COV}$ de 2,85 a $36,0 \mathrm{gDQO} / \mathrm{L}$.d com 0,4 a 0,2 $\mathrm{gHCO}_{3} / \mathrm{gDQO}$. A remoção de $\mathrm{DQO}$ variou de 43 a $78 \%$ a $55^{\circ} \mathrm{C}$ e de 75 a $85 \%$ a $35^{\circ} \mathrm{C}$. A suplementação de alcalinidade mostrou-se essencial para a estabilidade do processo, sendo requerida em menor quantidade a $35^{\circ} \mathrm{C}$.
\end{abstract}

Palavras-chave: processo anaeróbio; termofílico; mesofilico; alcalinidade; $\mathrm{NaHCO}_{3}$.

\section{Abstract}

The influence of the sodium bicarbonate $\left(\mathrm{NaHCO}_{3}\right)$ on the performance of an anaerobic sequencing batch biofilm reactor treating vinasse at 55 and $35^{\circ} \mathrm{C}$ was evaluated. The reactor was filled with polyurethane foam and agitated at $300 \mathrm{rpm}$. The acclimatization period at $55^{\circ} \mathrm{C}$ lasted 50 days, and the reactor was fed with vinasse (COD from 0.3 to $1.0 \mathrm{~g} / \mathrm{L}$ ). A previous enrichment of methanogenic population was provided for the reactor operated at $35^{\circ} \mathrm{C}$, feeding it with an ethanol based substrate $(2.5 \mathrm{gCOD} / \mathrm{L})$ during 21 days. Further on, organic loading rates (OLR) ranging from 0.85 to $5.70 \mathrm{gCOD} / \mathrm{L} . \mathrm{d}$ were applied to the reactor at $55^{\circ} \mathrm{C}$, supplemented with 1.2 to $0.4 \mathrm{gHCO}_{3} / \mathrm{gCOD}$. At $35^{\circ} \mathrm{C}$ the reactor was subjected to OLR ranging from 2.85 to $36.0 \mathrm{gCOD} / \mathrm{L}$. $\mathrm{d}$ with 0.4 to $0.2 \mathrm{gHCO}_{3} / \mathrm{gCOD}$. COD removal ranged from 43 to $78 \%$ at $55^{\circ} \mathrm{C}$ and from 75 to $85 \%$ at $35^{\circ} \mathrm{C}$. Alkalinity supplementation was found to be essential for process stability, but the amount required was lower at $35^{\circ} \mathrm{C}$.

Keywords: anaerobic process; thermophilic, mesophilic; alkalinity; $\mathrm{NaHCO}_{3}$.

\section{Introdução}

O Brasil é o maior produtor mundial no complexo sucroalcooleiro, exercendo a liderança nos segmentos de açúcar e álcool. O Estado do Paraná destaca-se como segundo maior produtor de álcool do país, com produção de 2 milhões de metros cúbicos na última safra (ALCOPAR, 2008).

A agroindústria sucroalcooleira exerce influências diretas nas áreas adjacentes às usinas no aspecto social, gerando empregos, aumentando a renda agrícola e fixando o homem no campo; no aspecto ambiental, causa impacto, que é ampliado devido às grandes extensões de áreas monocultivadas, práticas agrícolas, uso de agrotóxicos, queimada da cana-de-açúcar e disposição, em muitos casos, indiscriminada da vinhaça, resíduo líquido do processo de destilação do álcool (OMETTO, 2000).

$\mathrm{O}$ processamento industrial da cana resulta na geração de grande quantidade de resíduos como bagaço, cinzas, vinhaça, outros resíduos líquidos e emissões gasosas (VACCARI et al., 2005). A maioria desses resíduos tem alto teor de matéria orgânica que, se tratada adequadamente, pode resultar em fonte potencial de energia (RAJESHWARI et al., 2000). 
Como exemplo, pode ser citada a vinhaça, que é formada na proporção média de 12,5 L para cada litro de álcool produzido, com potencial poluidor - expresso em DQO (demanda química de oxigênio) - que pode alcançar $100 \mathrm{~g} / \mathrm{L}$. O pH é baixo (em torno de 4,5) e a temperatura é elevada $\left(90^{\circ} \mathrm{C}\right)$. Contém grande quantidade de sais minerais, com destaque para o potássio (em torno de 5,0 g/L). A carga poluidora é sempre elevada, mas varia em função das características da usina e da eficiência do processo de produção (WILKIE et al., 2000).

Para contornar os problemas ambientais causados pela vinhaça, diversas normas e leis foram estabelecidas no Brasil. Em março de 2005, foi homologada a Norma Técnica CETESB P4.231, com objetivo de estabelecer os critérios e procedimentos para a aplicação de vinhaça, gerada pela atividade sucroalcooleira no processamento da cana-de-açúcar no Estado de São Paulo. A referida norma considerou aspectos da Legislação Federal e Estadual, além de normas técnicas ABNT e CETESB para estabelecer os critérios e procedimentos propostos para a utilização da vinhaça (LUZ, 2005). No Estado do Paraná, o Instituto Ambiental do Paraná vem estudando medidas para a disposição da vinhaça, considerando seu teor de potássio e o solo onde será disposta. Atualmente, é permitida a aplicação máxima de até $150 \mathrm{~m}^{3} / \mathrm{ha}$.ano, independentemente do tipo de solo e da composição da água residuária.

Desde 1978, há no Brasil uma Portaria do Ministério do Estado do Interior (n. 323, de 1978) que proibiu, a partir da safra de 1979/1980, o lançamento direto de vinhaça em qualquer corpo hídrico pelas destilarias de álcool instaladas no país. Tal portaria exigia que as usinas apresentassem, no prazo determinado de três meses, projetos para implantação de sistemas adequados de tratamento e/ou utilização da vinhaça, visando ao controle da poluição hídrica.

Como alternativa tecnológica para reduzir o potencial poluidor da vinhaça quanto à matéria orgânica, destaca-se o processo anaeróbio, que gera produtos finais de valor econômico como o gás metano combustível e o efluente que pode ser usado com maior segurança como fertilizante de solos, com reduzida quantidade de matéria orgânica, mas ainda com concentrações consideráveis de nutrientes (MADEJÓN et al., 2001).

Novas configurações de reatores anaeróbios para conversão da matéria orgânica em biogás têm merecido a atenção dos pesquisadores com a intenção de aperfeiçoar o processo. Nesse contexto, devido à sua flexibilidade operacional (KENNEDY et al., 1991) e à possibilidade de aplicação a diversos tipos de águas residuárias, o reator anaeróbio operado em bateladas sequenciais (AnSBBR, do inglês Anaerobic Sequencing Batch Biofilm Reactor) tem sido amplamente investigado com vários tipos de águas residuárias, tanto em condições de temperatura mesofílica (em torno de $35^{\circ} \mathrm{C}$ ), como termofílica $\left(55^{\circ} \mathrm{C}\right)$.

Muitos pesquisadores consideram que os processos termofílicos têm maior eficiência na degradação de matéria orgânica em comparação com processos mesofílicos, porque pode ser obtida maior produção de biogás (ZÁBRANSKÁ et al., 2002). No entanto, os processos anaeróbios de efluentes com alta carga orgânica geram maior quantidade de ácidos voláteis, o que pode provocar um desbalanceamento entre a produção e consumo de ácidos, seguido por distúrbios da população metanogênica, que cresce mais lentamente que as populações hidrolíticas e fermentativas (AHRING, 1994; VAN LIER, 1995)

A concentração do ácido propiônico é outro fator limitante ao desempenho de processos anaeróbios termofílicos. Essa concentração pode representar até $66 \%$ da DQO total dos ácidos orgânicos (WIEGANT et al., 1985). Segundo Öztürk (1991), somente após as concentrações de ácidos butírico e acético serem consumidas, o ácido propiônico começa a ser degradado. Enquanto persistirem condições para a formação de ácido propiônico, ou seja, pressão parcial de $\mathrm{H}_{2}$ elevada, as bactérias acetogênicas não convertem o propiônico a acético.

Quando o sistema acumula grande quantidade de ácidos orgânicos ou em casos eventuais de instabilidade, uma opção para preservar a biomassa mantendo-se o pH próximo à neutralidade é adicionar substâncias alcalinizantes, como o bicarbonato de sódio, visto que o bicarbonato já é um produto final da metanogênese (SPEECE, 1996; GRIFFIN et al., 1998; TORRES LOZADA et al., 2005).

A falta de bicarbonato influencia no desempenho total do reator. Paulo et al. (2003) avaliaram o efeito do pH e do bicarbonato na conversão anaeróbia de metanol sob condições termofílicas e verificaram que o bicarbonato contribuiu diretamente para a conversão do etanol em aproximadamente $50 \%$ do total de metano formado. A conversão dos 50\% restantes dependeria da ocorrência da homoacetogênese que, no caso, estava restrita pela quantidade de bicarbonato disponível.

Paulo et al. (2003) controlaram o pH pela adição de outras substâncias químicas para comparação. Observaram que o pH do reator UASB foi mantido próximo ao neutro com $\mathrm{NaOH}$, mas o sistema mostrou queda de desempenho e instabilidade. Os autores sugeriram que o pH do sistema anaeróbio fosse controlado pela adição de tampão fosfato de $72 \mathrm{mM}$.

Torres Lozada et al. (2005) avaliaram três substâncias alcalinizantes comerciais: cal hidratada $\left(\mathrm{Ca}(\mathrm{OH})_{2}\right)$, hidróxido de sódio $(\mathrm{NaOH})$ e bicarbonato de sódio $\left(\mathrm{NaHCO}_{3}\right)$, com as finalidades de neutralizar a acidez em pH 5,75 da água residuária do processamento de mandioca e garantir a capacidade tampão de sistemas anaeróbios a baixo custo. As doses de alcalinidade a bicarbonato foram definidas a partir da quantidade mínima, que assegurou um valor adequado de atividade metanogênica específica (ao redor de 0,20 gDQO/gSVT.d; SVT: sólidos voláteis totais), sendo esses valores de 500 mg/L para $\mathrm{NaHCO}_{3}, 1.000 \mathrm{mg} / \mathrm{L}$ para $\mathrm{NaOH}$ e 1.750 $\mathrm{mg} / \mathrm{L}$ para $\mathrm{Ca}(\mathrm{OH})_{2}$. No estudo, os autores citaram que a cal hidratada apresentou menor custo (US\$ $0,16 / \mathrm{m}^{3}$ ), mas requer maior 
aporte de alcalinidade a bicarbonato, o que eleva o custo total (US\$ $0,69 / \mathrm{m}^{3}$ ). Já o custo total do $\mathrm{NaOH}$ foi menor, comparado com os outros alcalinizantes (US $\$ 0,54 / \mathrm{m}^{3}$ ), mas igual ao custo obtido com bicarbonato de sódio (US\$ $0,54 / \mathrm{m}^{3}$ ). Por fim, os autores concluíram que, considerando a razão custo/benefício, pode-se afirmar que o bicarbonato de sódio ofereceu os melhores resultados para garantir a capacidade tampão do sistema, com vantagens sobre os outros alcalinizantes por ser bastante solúvel, de fácil manipulação e evitar problemas de vácuo no sistema, como ocorre com o $\mathrm{NaOH}$ que, ao reagir com $\mathrm{CO}_{2}$ do meio, provoca diminuição da pressão interna do sistema.

Portanto, o objetivo deste trabalho foi avaliar a influência que o bicarbonato de sódio adicionado ao afluente teve no desempenho do reator anaeróbio operado em batelada sequencial contendo biomassa imobilizada no tratamento da vinhaça a 55 e a $35^{\circ} \mathrm{C}$.

\section{Material e métodos}

O reator de bancada AnSBBR tinha volume total e útil de 7,2 e 3,5 L, respectivamente. O sistema foi composto por dois cilindros concêntricos com diâmetros internos de 19,0 e 22,0 cm, ambos com altura de $25,0 \mathrm{~cm}$. O espaço entre as paredes interna e externa dos cilindros foi preenchido com água quente que recirculava constantemente de um banho externo mantido a $55 \pm 2{ }^{\circ} \mathrm{C}$ (condição termofílica) e $35 \pm 2{ }^{\circ} \mathrm{C}$ (condição mesofílica).

O reator foi preenchido com cubos de espuma de poliuretano de 1,0 $\mathrm{cm}$ de aresta (densidade aparente de $23 \mathrm{~kg} / \mathrm{m}^{3}$ e $95 \%$ porosidade) para imobilização da biomassa. As espumas foram colocadas dentro de uma cesta cilíndrica perfurada (mesh de $0,5 \mathrm{~cm}$ ) de aço inoxidável com diâmetros interno e externo de 7,0 e $17,5 \mathrm{~cm}$, respectivamente, e altura de $18,0 \mathrm{~cm}$. Essa cesta foi colocada dentro do reator.

O sistema foi agitado mecanicamente a $300 \mathrm{rpm}$ por impelidores, cuja haste foi colocada no cilindro interno do centro da cesta de aço. O aparato experimental usado nesta pesquisa está mostrado na Figura 1.

As matrizes cúbicas de espuma foram inoculadas com lodo anaeróbio granular (contendo $36 \mathrm{mg}$ de sólidos voláteis totais/g de lodo) retirado de um reator UASB que tratava água residuária de abatedouro de aves em temperatura ambiente (aproximadamente, $25^{\circ} \mathrm{C}$ ).

A temperatura inicial da operação do reator foi $35^{\circ} \mathrm{C}$. Após 21 dias de inoculação, a temperatura do reator termofílico foi aumentada abruptamente de 35 para $55^{\circ} \mathrm{C}$, enquanto a temperatura do reator mesofílico foi mantida em $35^{\circ} \mathrm{C}$ até o final do experimento.

As etapas de enchimento e descarga do sistema foram realizadas por bombas diafragmáticas comandadas por temporizadores. $\mathrm{O}$ tempo de enchimento e descarga era de dez minutos. O tempo de reação foi variável em cada fase e não houve tempo de sedimentação, uma vez que o reator continha material suporte para imobilização da biomassa.
A vinhaça foi coletada no canal de saída da indústria e estocada em refrigerador a $4^{\circ} \mathrm{C}$. O meio de alimentação do reator experimental foi vinhaça diluída de acordo com a concentração orgânica de cada fase experimental. Esse meio foi enriquecido com uma solução de sais minerais (fósforo, cobalto e selênio) e $\mathrm{NaHCO}_{3}$ para corrigir o pH. As cargas orgânicas volumétricas (COV) aplicadas variaram de 1,0 a 6,6 gDQO/L.d para o reator termofílico e entre 2,5 e 36,0 gDQO/L.d para o reator mesofílico (Tabela 1). Depois da inoculação, o reator termofílico foi adaptado tanto ao aumento de temperatura como à água residuária por 50 dias.

O reator mesofílico foi enriquecido nos primeiros 17 dias com etanol (correspondendo a 2,5 gDQO/L), sais minerais e solução de bicarbonato para desenvolver micro-organismos metanogênicos.

A quantidade de bicarbonato de sódio para as respectivas COV expressas em g DQO/L.d, aplicadas no AnSBBR termofílico e mesofílico, está apresentada na Tabela 1.

A Tabela 2 apresenta a composição da solução de nutrientes adicionada ao substrato, conforme proposto por Del Nery (1987).

O desempenho do AnSBBR foi avaliado pelo monitoramento do afluente e efluente pelas análises de DQO, sólidos totais (ST), sólidos voláteis totais (SVT) e pH (APHA et al. 1995). A alcalinidade a bicarbonato (AB) foi determinada pelo método de DiLallo e Albertson (1961), modificado por Ripley, Boyle e Converse (1986). Os ácidos voláteis totais (AVT) foram avaliados conforme proposto por DiLallo e Albertson (1961).

A evolução e dinâmica populacional de micro-organismos foram baseadas em observações microscópicas dos morfotipos presentes na biomassa ao longo da operação do sistema. Em cada fase, amostras de cubos das espumas de poliuretano foram retiradas do reator em

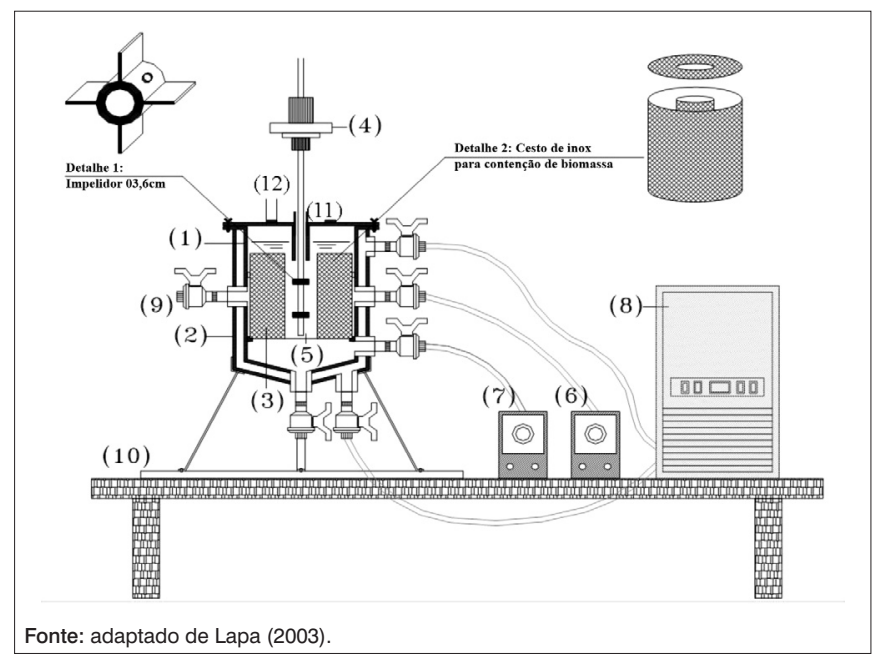

Figura 1 - Esquema do reator anaeróbio em batelada sequencial, onde: (1) reator anaeróbio em batelada sequencial; (2) camisa de aquecimento; (3) cesto inoxidável; (4) agitador mecânico; (5) impelidor; (6) bomba de enchimento; (7) bomba de descarga; (8) banho ultratermostatizado; (9) amostrador; (10) bancada; (11) selo mecânico; (12) saída de biogás do headspace. 
Tabela 1 - Quantidade de bicarbonato adicionada (em relação à DQ0) ao reator anaeróbio operado em bateladas sequenciais (AnSBBR) termofilico e mesofilico

\begin{tabular}{|c|c|c|c|c|c|c|}
\hline \multirow{2}{*}{ Fases } & \multicolumn{3}{|c|}{ Termofílico } & \multicolumn{3}{|c|}{ Mesofílico } \\
\hline & COV (g/L.d) & $\mathrm{gHCO}_{3} / \mathrm{gDQO}$ & $\mathrm{gHCO}_{3}^{-} /$L.d & COV (g/L.d) & $\mathrm{gHCO}_{3} / \mathrm{gDQO}$ & $\mathrm{gHCO}_{3} /$ L.d \\
\hline Adaptação & 0,97 & 1,2 & 1,16 & 3,41 & 1 & 3,41 \\
\hline 1 & 0,85 & 1,2 & 1,02 & 2,79 & 0,4 & 1,12 \\
\hline II & 2,54 & 0,8 & 2,03 & 6,44 & 0,4 & 2,58 \\
\hline III & 3,64 & 0,8 & 2,91 & 7,92 & 0,3 & 2,38 \\
\hline IV & 4,50 & 0,6 & 2,70 & 10,56 & 0,2 & 2,11 \\
\hline V & 4,00 & 0,6 & 2,40 & 22,23 & 0,2 & 4,45 \\
\hline $\mathrm{VI}$ & 5,70 & 0,4 & 2,28 & 35,94 & 0,2 & 7,19 \\
\hline VII & 5,24 & 0,6 & 3,14 & - & - & - \\
\hline
\end{tabular}

COV: cargas orgânicas volumétricas.

Tabela 2 - Composição da solução de nutrientes para processos anaeróbios

\begin{tabular}{lcc|} 
Composto & & Concentração $(\mathrm{mg} / \mathrm{L})$ \\
\hline DQO & & 1.000 \\
\hline Sulfato de níquel & $\left(\mathrm{NiSO}_{4} \cdot 6 \mathrm{H}_{2} \mathrm{O}\right)$ & 0,5 \\
Sulfato ferroso & $\left(\mathrm{FeSO}_{4} \cdot 7 \mathrm{H}_{2} \mathrm{O}\right)$ & 2,5 \\
\hline Cloreto férrico & $\left(\mathrm{FeCl}_{3} \cdot 6 \mathrm{H}_{2} \mathrm{O}\right)$ & 0,25 \\
\hline Cloreto de cálcio & $\left(\mathrm{CaCl}_{2} \cdot 6 \mathrm{H}_{2} \mathrm{O}\right)$ & 23,5 \\
\hline Cloreto de cobalto & $\left(\mathrm{CoCl}_{2} \cdot 6 \mathrm{H}_{2} \mathrm{O}\right)$ & 0,066 \\
\hline Dióxido de selênio & $\left(\mathrm{SeO}_{2}\right)$ & 0,035 \\
\hline Fosfato de sódio dibásico & $\left(\mathrm{Na}_{2} \mathrm{HPO}_{4} \cdot \mathrm{H}_{2} \mathrm{O}\right)$ & 15
\end{tabular}

Fonte: Del Nery (1987).

perfil vertical. As amostras foram examinadas por microscopia óptica com e sem fluorescência.

\section{Resultados e discussões}

\section{Partida dos reatores}

O inóculo apresentou abundante diversidade de morfologias microbianas, tais como bacilos de diversas formas, cocos agrupados e células semelhantes às arqueas Methanosaeta e Methanosarcina.

Quando a temperatura do reator termofílico foi aumentada repentinamente de 35 para $55^{\circ} \mathrm{C}$, conforme sugerido por Pender et al. (2004), no $21^{\circ}$ ciclo com 1,0 gDQO/L.d, a eficiência de remoção de DQO foi de 30\%. Na tentativa de adaptar o inóculo à vinhaça, em ambas as temperaturas, o reator teve uma fase inicial em que foi necessário adicionar solução de sais minerais, além do bicarbonato.

A mudança de temperatura operacional foi acompanhada pelo aumento de bicarbonato de 0,7 para $1,0 \mathrm{gHCO}_{3} / \mathrm{gDQO}$ (1:1) como medida preventiva para evitar colapso do reator em maior temperatura pela aceleração das reações e, consequentemente, aumento da produção de ácidos voláteis. A COV foi diminuída de 1,0 para 0,5 gDQO/L.d e o tempo de ciclo foi aumentado de 1 para 2 dias.
Aumento da diversidade de morfologias foi observado no ciclo 39 (50 dias), indicando que o reator termofílico estava adaptado. Morfologias semelhantes à Methanosaeta, Methanosarcina, bactérias redutoras de sulfato, além de bacilos diversos, foram observadas ao longo do perfil vertical do reator (Figura 2).

Quando o reator foi operado sob condição mesofílica a $35^{\circ} \mathrm{C}$, houve novo aporte de inóculo, o tempo de ciclo foi fixado em 1 dia e a COV inicial era de 1,0 gDQO/L.d. Nessa fase, o reator foi abastecido somente com etanol, sais minerais e bicarbonato na relação de 1:1, com aumentos gradativos de DQO e diminuição da relação de $\mathrm{HCO}_{3}$-/DQO nos ciclos subsequentes. A redução de bicarbonato adicionado era feita com a intenção de adaptar a biomassa utilizando a menor quantidade possível dessa substância, cuja adição ao processo representa aumento substancial de custos operacionais do sistema de tratamento para as empresas.

Dessa forma, já no ciclo 17 , a relação $\mathrm{HCO}_{3}$-/DQO era de 0,10 e a COV, de 5,0 g/L.d, ainda com etanol para desenvolver mais a população metanogênica. Do $18^{\circ}$ ao $21^{\circ}$ ciclo, o etanol foi substituído por vinhaça, a COV foi diminuída para 2,5 gDQO/L.d e a relação $\mathrm{HCO}_{3}$-/DQO foi aumentada para 0,40, medidas adotadas também para evitar efeito negativo pela troca de substrato. Nessas condições experimentais, o reator apresentou eficiência de remoção de DQO de $70 \%$, tendo ocorrido seleção de morfologias semelhantes a bacilos de diversas formas e Methanosaeta. A estabilidade de desempenho do reator foi um dos parâmetros de consideração de que a biomassa estava adaptada às condições operacionais, bastando, a partir de então, adaptá-la a carregamentos orgânicos crescentes.

\section{Fases operacionais}

A Tabela 3 mostra a tendência do desempenho do AnSBBR, tanto sob condição termofílica como mesofílica. Observou-se que, na condição termofílica, o reator apresentou instabilidade operacional em todas as fases experimentais, com queda na eficiência imediatamente após o aumento da COV que ocorreu em cada mudança de fase (Figura 3A). Esse aumento era feito em função da resposta do 

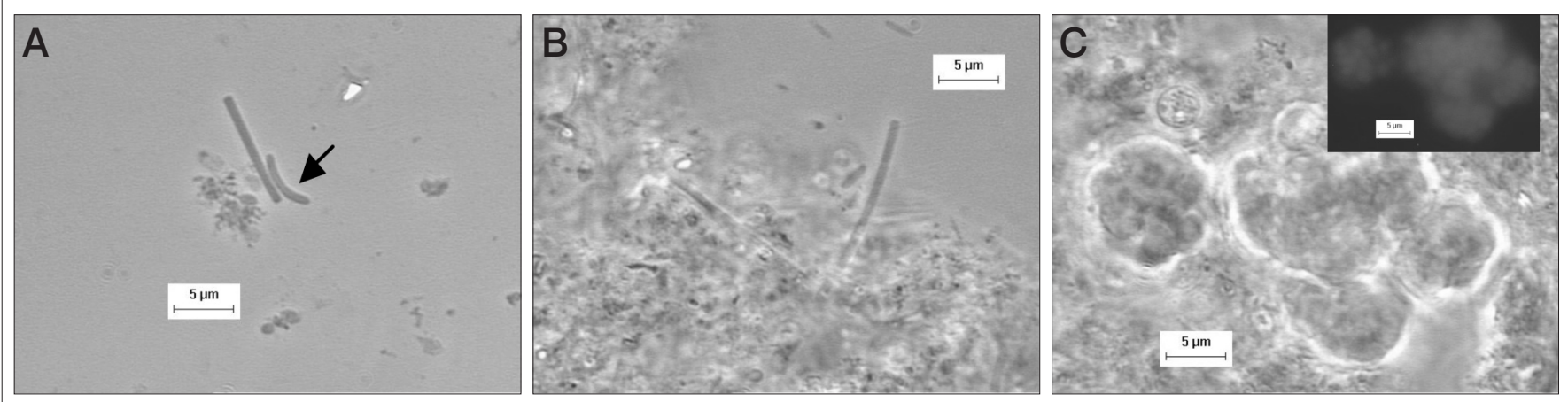

Figura 2 - Morfologias observadas na biomassa do reator ao final da fase de adaptação em condições termofílicas $\left(55^{\circ} \mathrm{C}\right)$ em microscópio óptico com aumento de 1.500X: (A) possível Methanosaeta e bactéria redutora de sulfato, bacilos curvos (seta); (B) Methanosaeta e bacilos; (C) estrutura semelhante a células de Methanosarcina e, em detalhe, a foto em fluorescência.

reator. Assim, foi possível observar também que o aumento de COV teve que ser suave em condições termofilicas, em comparação com os aumentos de COV no reator mesofílico.

No reator termofílico, a partir da fase II com COV de $2,5 \mathrm{~g} / \mathrm{L} . \mathrm{d}$, foi necessário aumentar o tempo de ciclo de acordo com a concentração orgânica aplicada nas fases seguintes para garantir eficiência de remoção de, pelo menos, $60 \%$ da DQO aplicada.

$\mathrm{Na}$ fase I, com COV de 1,0 g/L.d e tempo de ciclo de 1 dia (ciclo 40 a 48), o reator termofílico apresentou, em média, remoção de DQO de 43\%, alcalinidade a bicarbonato de $958 \pm 98 \mathrm{mg} / \mathrm{L}$, com uma relação alcalinidade a bicarbonato efluente/DQO adicionada (AB/DQO) de 1,23 a 1,55 (Figura 3A) e concentração de ácidos propiônico e acético de 10 e $30 \mathrm{mg} / \mathrm{L}$, respectivamente. Esse consumo parcial de ácido acético esteve provavelmente relacionado com a falta de nutrientes necessários para a conversão de ácidos orgânicos a metano no final do ciclo ou com as limitações do processo termofílico. Segundo Van Lier (1996), a presença de ácidos voláteis é uma das consequências do desequilíbrio de processos anaeróbios termofílicos, embora, com frequência, tenham sido observadas morfologias semelhantes às arqueas acetoclásticas consumidoras de acetato (como Methanosaeta) na primeira fase.

Apesar do aumento de COV a que o reator termofílico foi submetido para 2,5 g/L.d, tempo de ciclo de 1 dia (ciclo 49 a 70) e diminuição de $\mathrm{HCO}_{3}-1 \mathrm{DQO}$ de 1,2 (fase I) para 0,8 (fase II), houve aumento da eficiência ( $72 \%$ em média). Provavelmente, a quantidade de matéria orgânica aplicada anteriormente era insuficiente frente ao potencial de degradação da biomassa desenvolvida no reator. Por outro lado, o pH do efluente foi mantido em 7,9 \pm 0,6, acima da faixa ótima de pH para metanogênicas (SPEECE, 1996), sendo, portanto, necessária uma redução ainda maior de bicarbonato no afluente.

Nessa fase, o valor de sólidos voláteis no efluente aumentou de $559 \pm 97$ para $889 \pm 252 \mathrm{mg} / \mathrm{L}$ com o aumento da COV de 1,0 para $2,5 \mathrm{~g} / \mathrm{L} . \mathrm{d}$, respectivamente. Isso pode ter ocorrido pela maior perda de biomassa no interior do reator ou pelo aumento de sólidos voláteis

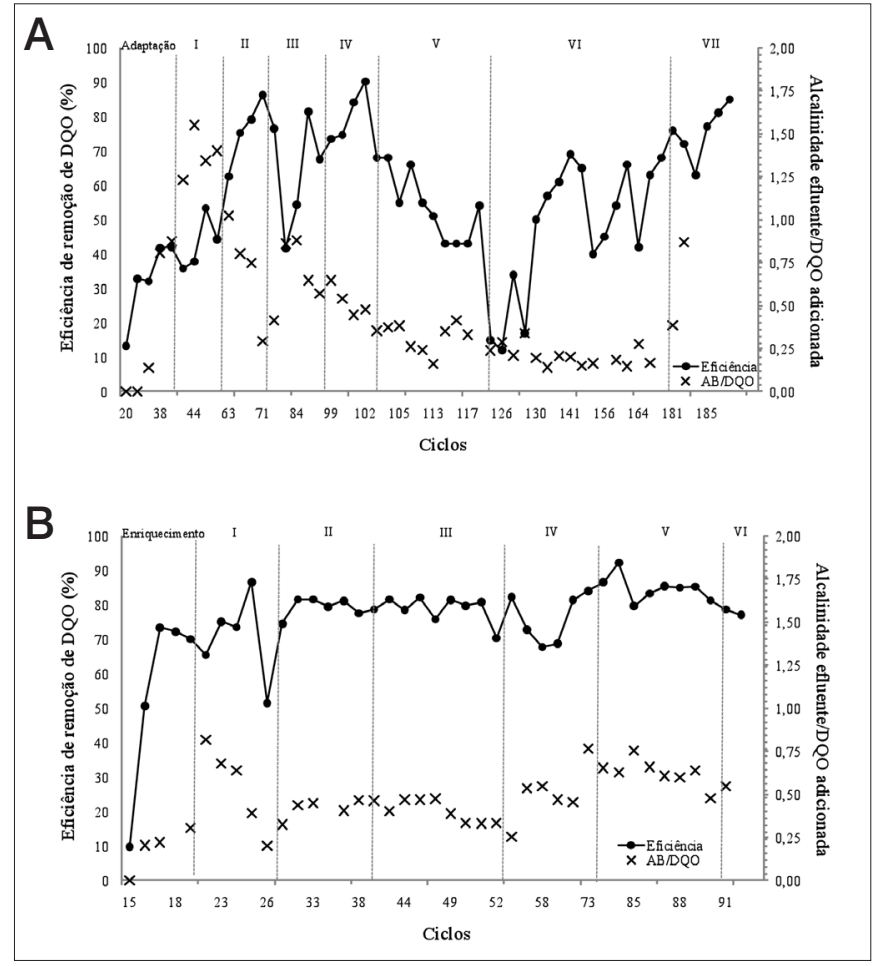

Figura 3 - Desempenho do reator quanto à eficiência de remoção de DQO e relação alcalinidade a bicarbonato do efluente/DQ0 adicionada em condições termofilicas (A) e mesofilicas (B).

no reator, devido ao aumento da concentração orgânica. No final do ciclo 48, verificou-se acúmulo de cerca de $100 \mathrm{mg} / \mathrm{L}$ de ácido propiônico e de $10 \mathrm{mg} / \mathrm{L}$ de ácido acético.

Observa-se, na Tabela 3, que os valores de desvio padrão obtidos no reator mesofílico foram menores do que no termofílico, constatando-se, portanto, que, sob condições mesofílicas, o processo foi mais estável.

A COV máxima alcançada pelo reator termofilico foi de $5,7 \mathrm{~kg} / \mathrm{m}^{3} . \mathrm{d}$, com 46\% de eficiência média de remoção na fase VI (ciclo 169) com 263 dias de operação e, pelo mesofilico, foi de $36 \mathrm{~kg} / \mathrm{m}^{3}$.d, com 79\% de remoção na fase VI em 90 dias de operação (Figura 3). 
Tabela 3 - Carga orgânica volumétrica (COV) aplicada ao reator anaeróbio operado em bateladas sequenciais (AnSBBR), eficiência de remoção de DQO e desvio padrão (DP) sob condições termofílicas e mesofílicas

\begin{tabular}{lcccccc} 
& \multicolumn{3}{c}{ Termofílico } & \multicolumn{4}{c}{ Mesofílico } \\
\cline { 2 - 7 } Fases & COV & $\begin{array}{c}\text { Remoção de } \\
\text { DQO (\%) }\end{array}$ & \pm DP & COV & $\begin{array}{c}\text { Remoção de } \\
\text { DQO (\%) }\end{array}$ & \pm DP \\
I & 0,85 & 43 & 7,9 & 2,50 & 75 & 8,7 \\
\hline II & 2,54 & 72 & 8,7 & 6,40 & 76 & 9,6 \\
III & 3,64 & 68 & 19,2 & 7,90 & 78 & 4,1 \\
\hline IV & 4,50 & 78 & 9,0 & 10,50 & 78 & 7,7 \\
V & 4,00 & 55 & 10,0 & 22,20 & 85 & 4,1 \\
\hline VI & 5,70 & 46 & 19,2 & 36,00 & 79 & 2,1 \\
\hline VII & 5,20 & 75 & 7,5 & & & \\
\hline
\end{tabular}

Tabela 4 - Quantidade de $\mathrm{Na}^{+}$adicionada no afluente junto do bicarbonato em cada fase experimental nos reatores termofílico e mesofílico

\begin{tabular}{lcc|}
\multirow{2}{*}{ Fase } & \multicolumn{2}{c}{$\mathrm{mg} \mathrm{Na}^{+} / \mathrm{L}$} \\
\cline { 2 - 3 } & Termofílico & Mesofílico \\
\hline I & 534 & 1.286 \\
II & 385 & 421 \\
III & 766 & 971 \\
IV & 1.647 & 896 \\
V & 3.047 & 796 \\
\hline VI & 5.425 & 1.676 \\
VII & 1.816 & 2.710 \\
\hline
\end{tabular}

Viana (2006) tratou vinhaça de cana-de-açúcar em UASB termofílico $\left(55^{\circ} \mathrm{C}\right)$ com tempo de detenção hidráulica (TDH) de 24 horas, aplicando COV de 0,3 a 6,5 g DQO/L.d com adição de 1,2 a 0,5 $\mathrm{HCO}_{3}{ }^{-} / \mathrm{DQO}$, respectivamente, por um tempo de funcionamento total de 200 dias. O autor observou que houve estabilidade operacional do reator até a COV de 5,0 g/L.d com remoção média de 50\%. Para a COV de 6,5 g/L.d, o autor observou queda de eficiência na remoção de DQO de $40 \%$ e aumento de ácidos voláteis totais de 800 (COV de 5,0 g/L.d) para $1.200 \mathrm{mg} / \mathrm{L}$ (COV de 6,5 g/L.d), apesar de não ter sido observada queda nos valores de $\mathrm{pH}$ e de alcalinidade a bicarbonato.

Comparando-se os resultados experimentais obtidos, observa-se que o AnSBBR operado a $35^{\circ} \mathrm{C}$ apresentou melhores resultados, apesar de ter recebido quantidades inferiores de bicarbonato de sódio, conforme pode ser visualizado na Figura 3B e na Tabela 4. Esse resultado difere do obtido por outros autores que trabalharam com outras águas residuárias, os quais alcançaram melhores resultados com reatores operados à temperatura termofílica.

Uma possível explicação para esses resultados é que o inóculo usado para ambos os reatores foi lodo de um UASB operado à temperatura ambiente. Esse fato pode ter proporcionado maior capacidade de adaptação do inóculo no tratamento da vinhaça de cana-de-açúcar no reator mesofílico, já que não houve grande variação de temperatura do UASB ao AnSBBR mesofílico.

Observou-se que, na fase de maior estabilidade do reator termofílico (fases III, IV e V), o pH variou de 8,2 a 8,5, sendo que os valores de $\mathrm{pH}$ no reator operado na temperatura mesofílica ficaram abaixo de 8,0.

No trabalho desenvolvido por Song et al. (2004) com lodo de esgoto, o $\mathrm{pH}$ medido de processos termofílicos sempre era mais elevado $(8,08)$ que dos mesofílicos $(7,67)$. O mesmo comportamento foi observado com os valores de alcalinidade que, em média, foram de 6.875 contra $6.412 \mathrm{mgCaCO}_{3} / \mathrm{L}$ no efluente final do processo mesofílico. Os autores citam que o pH é resultado dos valores de alcalinidade da digestão anaeróbia termofílica, que é gerada a partir da degradação de compostos orgânicos, redução de sulfato e liberação de ortofosfato.

Mesmo operando o sistema em $\mathrm{pH}$ maior que o recomendado para micro-organismos anaeróbios (entre 6,8 e 7,4), os autores anteriormente citados não observaram efeito negativo na eficiência do sistema. Além disso, foi observado propionato no efluente e maior pressão parcial de hidrogênio. Claramente, os autores concluíram que o mesofílico apresentou melhor qualidade do efluente, maior rendimento de metano no biogás e estabilidade operacional. Em compensação, o termofílico apresentou maior redução de sólidos voláteis e redução de coliformes fecais.

Paulo et al. (2003) citam que a faixa ótima de pH para o crescimento de metanogênicos termofílicos situa-se entre 6,5 e 8,0 e de homoacetogênicos, entre 5,8 e 7,0.

A estabilidade do reator mesofílico avaliada nesse trabalho foi verificada não somente pelo desempenho na eficiência de remoção de DQO, como também pela alcalinidade a bicarbonato observada no efluente (relação AB/DQO, Figura 3).

Comparando-se a quantidade de bicarbonato adicionado ao afluente do reator, pode-se verificar, comparativamente, que houve menor suplementação no reator mesofílico do que no termofílico, conforme apresentado pela Tabela 1.

No trabalho de Paulo et al. (2003), observou-se que a conversão de metanol foi influenciada pelo bicarbonato no consórcio anaeróbio, pois consumiu $\mathrm{o} \mathrm{H}_{2}$ pela produção de acetato pela homoacetogênese a partir de bicarbonato e hidrogênio, permitindo manter a pressão parcial de hidrogênio baixa para que a reação fosse termodinamicamente favorável e o metanol pudesse ser convertido em $\mathrm{H}_{2} / \mathrm{CO}_{2}$. Isso torna-se especialmente importante no tratamento de águas residuárias que contêm metanol.

Como a fonte de bicarbonato usada no presente trabalho experimental foi bicarbonato de sódio, e sabendo-se que o íon de sódio $\left(\mathrm{Na}^{+}\right)$, a partir da concentração de $3.500 \mathrm{mg} / \mathrm{L}$, pode apresentar toxicidade à biomassa anaeróbia (McCARTY, 1964 apud GRIFFIN et al., 1998), calculou-se a quantidade de $\mathrm{Na}^{+}$que foi adicionado em cada fase experimental (Tabela 4). 
Observa-se também na Tabela 4 que, na quinta fase do reator termofílico, foi adicionada grande quantidade de $\mathrm{Na}^{+}$, o que pode também ter prejudicado os micro-organismos anaeróbios, contribuindo, juntamente com a COV, para uma queda brusca de desempenho do reator. Já no reator mesofílico, observa-se que o $\mathrm{Na}^{+}$adicionado não ultrapassou o nível de toxicidade citado.

Olmo (2006) estudou o efeito do sódio sobre o tratamento de água residuária de charqueada em elevada salinidade em reatores UASB e observou que o desempenho dos reatores quanto à remoção de matéria orgânica não foi alterado até a concentração de $\mathrm{NaCl}$ de $6.000 \mathrm{mg} / \mathrm{L}$.

Outro resultado interessante observado nesse trabalho foi a diferença quanto às morfologias observadas nos exames de microscopia ótica realizados nos reatores termofílico e mesofílico. Ao final dos experimentos, o reator termofílico era colonizado por arqueas semelhantes à Methanosarcina, enquanto que o reator mesofílico selecionou arqueas semelhantes às do tipo Methanosaeta.

Viana (2006), tratando vinhaça de cana-de-açúcar, também observou que houve colonização predominante de arqueas do gênero Methanosarcina no lodo biológico de um reator UASB, sob condições termofílicas. E, nesse período, o autor não observou instabilidade operacional.

\section{Conclusões}

Diante dos desempenhos dos reatores e das morfologias observadas neste trabalho, pode-se concluir que a instabilidade observada no AnSBBR termofílico pode estar associada à conjunção dos fatores relacionados à composição da biomassa metanogênica e características físicas e operacionais dessa configuração de reator, pois o reator UASB, operado por Viana (2006), selecionou basicamente arqueas do gênero Methanosarcina e apresentou bons resultados de desempenho.

De acordo com as respostas dos reatores frente ao carregamento orgânico e a quantidade de bicarbonato adicionado ao sistema, ficou evidenciado que o reator operado a $35^{\circ} \mathrm{C}$ mostrou maior estabilidade operacional no tratamento anaeróbio da vinhaça de canade-açúcar e que o reator operado a $55^{\circ} \mathrm{C}$ era diretamente dependente da adição de bicarbonato. Mas, ainda que em menor quantidade, foi necessário adicionar bicarbonato ao reator mesofílico no período experimental, mostrando que a adição de bicarbonato foi essencial em ambas as temperaturas operacionais no AnSBBR para o tratamento de vinhaça.

Pode-se concluir que as condições em que o reator termofílico apresentou melhor desempenho foi com 0,6 g de $\mathrm{HCO}_{3}^{-} / \mathrm{gDQO}$ na COV de 4,50 e 5,24 g/L.d, e o reator mesofílico apresentou melhor desempenho com 0,2 g de $\mathrm{HCO}_{3}^{-}$/g DQO até a COV de 35,94 g/L.d.

\section{Agradecimentos}

À Fundação de Amparo à Pesquisa do Estado de São Paulo (FAPESP), ao Conselho Nacional de Pesquisa (CNPq) e à Coordenação de Aperfeiçoamento de Pessoal de Nível Superior (CAPES) pelo suporte financeiro concedido a esta pesquisa.

\section{Referências}

ALCOPAR. Associação de Produtos de Bionergia do Estado do Paraná. 2008. Disponível em <www.alcopar.org.br>. Acesso em: maio 2008.

Ahring, B.K. Status on science and application of thermophilic anaerobic digestion. Water Science and Technology, v. 30, n. 12, p. 241-250, 1994

APHA; AWWA; WEF. Standard methods for the examination of water and wastewater. 19 ed. Washington D.C., 1995.

DEL NERY, V. Utilização de lodo anaeróbio imobilizado em gel no estudo de partida de reatores de fluxo ascendente com manta de lodo. Dissertação (Mestrado em Hidráulica e Saneamento), Escola de Engenharia de São Carlos, Universidade de São Paulo, São Carlos, SP, 1987.

Dilallo, R.; AlbertSon, O.E. Volatile acids by direct titration. Journal of Water Pollution Control Federation, v. 33, n. 4, p. 356-365, 1961.

Griffin, M.E. et al. Methanogenic population dynamics during start-up of anaerobic digesters treating municipal solid waste and biosolids. Biotechnology and Bioengineering, v. 57, n. 3, p. 342-355, 1998
Kennedy, K.J. et al. Performance of anaerobic sludge blanket sequencing batch reactors. Research Journal of Water Pollution Control Federation, v. 63, p. 75-83, 1991.

Lapa, K.R. Avaliação de desempenho do reator anaeróbio em batelada seqüencial (ASBR), contendo biomassa imobilizada em pedra pome para tratamento de esgoto sanitário. Dissertação (Mestrado em Engenharia Hidráulica e Saneamento), Escola de Engenharia de São Carlos, Universidade de São Paulo, São Carlos, SP, 2003.

Luz, P.H.C. Novas tecnologías no uso da vinhaça e alguns aspectos legais. In: SIMPÓSIO DE TECNOLOGIA DE PRODUÇÃO DE CANA-DEAÇUCAR, 2, Anais...São Paulo, 2005. p. 1-53, 2005.

Madejón, E. et al. Agricultural use of three (sugar-beet) vinasse composts: effect on crops and chemical properties of a Cambisol soil in the Guadalquivir river valley (SW Spain). Agriculture, Ecosystems \& Environment, v. 84, n. 1, p. 55-65, 2001

Olmo, L.N. Avaliação do antagonismo do efeito do sódio sobre o tratamento de água residuária de charqueada com elevada salinidade 
em reator anaeróbio de manta de lodo (UASB). Dissertação (Mestrado em Engenharia Hidráulica e Saneamento), Escola de Engenharia de São Carlos, Universidade de São Paulo, São Carlos, SP, 2006.

Ometto, A.R. Discussão sobre os fatores ambientais impactados pelo setor sucroalcooleiro e a certificação socioambiental. Dissertação (Mestrado em Ciências da Engenharia Ambiental), Escola de Engenharia de São Carlos, Universidade de São Paulo, São Carlos, 2000.

Öztürk, M. Conversion of acetate, propionate and butyrate to methane under thermophilic conditions in bath reactors. Water Science and Technology, v. 25, p. 1509-1513, 1991.

Paulo, P.L. et al. The anaerobic conversion of methanol under thermphilic conditions: $\mathrm{pH}$ and bicarbonate dependence. Journal of Bioscience and Bioengineering, v. 96, n. 3, p. 213-218, 2003.

Pender, S. et al. Long-term effects of operating temperature and suphate addition on the methanogenic community structure of anaerobic hybrid reactors. Water Research, v. 38, n. 3, p. 619-630, 2004

Rajeshwari, K.V. et al. State-of-the-art of anaerobic digestion technology for industrial wastewater treatment. Renewable and Sustainable Energy Reviews, v. 4, n. 2, p. 135-156, 2000

Ripley, L.E.; Boyle, W.C.; Converse, J.C. Improved alkalimetric monitoring anaerobic digestion of high-strenght wastes. Journal of Water Pollution Control Federation, v. 58, p. 406-411, 1986.

Speece, R.E. Anaerobic biotechnology for ind ustrial wastewater treatment. Nashville: Archae Press, 1996.

Song, Y.C.; Kwon, S.J.; Woo, J.H. Mesophilic and thermophilic temperature co-phase anaerobic digestion compared with singlestage mesophilic- and thermophilic digestion of sewage sludge. Water Research, v. 38, n. 7, p. 1653-1662, 2004.
Torres Lozada, P. et al. Evaluación de diferentes alcalinizantes en el tratamiento anaerobio de aguas residuales fácilmente acidificables. Caso: agua residual del proceso de extracción de almidón de yuca. In: TALLER Y SIMPOSIO LATINOAMERICANO SOBRE DIGESTION ANAEROBIA, 8, 2005, Punta del Este: Uruguay. Anais... Punta del Este, IWA. p. 571-575, 2005.

Vaccari, G. et al.Overview of the environmental problems in beet sugar processing: possible solutions. Journal of Cleaner Production, v. 13, n. 5, p. 499-507, 2005.

Van Lier, J.B. Limitations of thermophilic anaerobic wastewater treatment and the consequences for process design. Antonie van Leeuwenhoek, $\mathrm{v}$. 69, n. 1, p. 1-14, 1996.

. Thermophilic anaerobic wastewater treatment; temperature aspects and process stability. Tese (Doutorado). Wageningen University, Wageningen, The Netherlands, 1995.

Viana, A.B. Tratamento anaeróbio de vinhaça em reator UASB operado em temperaturas na faixa termofílica e submetido ao aumento progressivo de carga orgânica. Dissertação (Mestrado em Engenharia Hidráulica e Saneamento), Escola de Engenharia de São Carlos, Universidade de São Paulo, São Carlos, SP, 2006.

Wiegant, W.M.; Claassen, J.A.; Lettinga, G. Thermophilic anaerobic digestion of high strength wastewaters. Biotechonology and Bioengineering, v. 27, n. 9, p. 1374-1381, 1985.

Wilkie, A.C.; Riedesel, K.J.; Owens, J.M. Stillage characterization and anaerobic treatment of ethanol stillage from conventional and cellulosic feedstocks. Biomass and Bioenergy, v. 19, n. 2, p. 63-102, 2000.

Zábranská, J. et al. The contribution of thermophilic anaerobic digestion to stable operation of wastewater sludge treatment. Water Science and Technology, v. 46, n. 4-5, p. 447-453, 2002. 